\title{
Monitoring and Prediction of the Earth's Climate: A Future Perspective
}

\author{
Kevin E. TREnBerth \\ National Center for Atmospheric Research, ${ }^{*}$ Boulder, Colorado \\ BERRIEN MOORE \\ University of New Hampshire, Durham, New Hampshire \\ THOMAS R. KARL \\ National Climatic Data Center, Asheville, North Carolina \\ CARLOS Nobre \\ CPTECINPE, Sao Paulo, Brazil
}

(Manuscript received 11 August 2004, in final form 7 July 2005)

\begin{abstract}
The climate is changing because of human activities and will continue to do so regardless of any mitigation actions. Available climate observations and information are also changing as technological advances take place. Accordingly, an overview is given of a much-needed potential climate information system that embraces a comprehensive observing system to observe and track changes and the forcings of the system as they occur, and that develops the ability to relate one to the other and understand changes and their origins. Observations need to be taken in ways that satisfy the climatc monitoring principles and ensure long-term continuity, and that have the ability to discern small but persistent signals. Some benchmark observations are proposed to anchor space-based observations and trends, including a much-needed step forward in the quality of water vapor observations. Satellite observations must be calibrated and validated. with orbital decay and drift effects fully dealt with if possible, and adequate overlap to ensure continuity. The health of the monitoring system must be tracked and resources identified to address issues. Fields must be analyzed into global products and delivered to users while stakeholder needs are fully considered. Data should be appropriately archived with full and open access, along with metadata that fully describe the observing system status and environment in which it operates. Reanalysis of the records must be institutionalized along with continual assessment of impacts of new observing and analysis systems. Some products will be used to validate and improve models, as well as initialize models and predict future evolution on multiple time scales using ensembles. Attribution of changes to causes is essential, and it is vital to fully assess past changes and model performance and results in making predictions to help appraise reliability and assess impacts regionally on the environment, human activities, and scctors of the economy. In particular, a revolution in the way developing countrics use and apply climate information is expected. Such a system will be invaluable and further provides a framework for setling priorities of new observations and related activitics. Without the end-to-end process the investments will not deliver adequate return and our understanding will be much less than it would be otherwise.
\end{abstract}

\section{Introduction}

The climate is changing from human influences, and it is likely to continue to change regardless of the success of any mitigation actions owing to the long time

\footnotetext{
* The National Center for Atmospheric Research is sponsored by the National Science Foundation.

Corresponding author address: Kevin E. Trenberth, National Center for Atmospheric Research. P.O. Box 3000, Boulder, CO 80307

E-mail: trenbert@ucar.edu
}

scales involved in the energy infrastructure (related to fossil fuel burning), the long lifetime of carbon dioxide in the atmosphere, and the slow response of the oceans and cryosphere to change (e.g., Karl and Trenberth 2003). This creates an imperative for building a comprehensive climate information system to perform the following functions:

- observe and track the climate changes and forcings as they occur;

- analyze global products (often with data assimilation in models);

- understand the changes and their origins; 
- evaluate and improve models;

- initialize models; predict future developments; and

- assess impacts regionally: on environment, human activitics, and sectors such as agriculture, energy, fisheries, water resources, etc.

Such a system will be invaluable regardless of the magnitude of global warming (Trenberth et al. 2002).

Major technological advances are occurring now, and so we address the question in this paper as to what kind of information system might we have, and how do we accomplish it? There are many exciting new instruments on satellites being launched that open new horizons, and at the same time in situ instrumentation is also being developed to address observational issues that cannot be addressed from space (most notably in the oceans) and which provide a ground truth for the satellite observations. New global coupled climate models and even Earth System models are under development at NOAA's Geophysical Fluid Dynamics Laboratory (GFDL), the National Center for Atmospheric Research (NCAR), and elsewhere. Computer and information technology continues to advance, so that global climate models can be run at very high resolution, for instance on the Earth Simulator in Japan. Throughput in the range of many Teraflops is becoming possible. Simulating the earth's climate at a few kilometers resolution is becoming possible. Major frontiers include how to best utilize the multitude of observations on many different variables, for instance taking advantage of four-dimensional data assimilation. Other frontiers exist in very high-resolution land data assimilation (e.g.. Mitchell et al. 2004) that results in highresolution hydrological information on streamflow and water balance (Lohmann et al. 2004). In the future, it is anticipated that fully coupled data assimilation will become developed and fcasible, but this is not practicable at present.

In spite of all these major technological advances, a comprehensive climate observing system does not exist. The latter was defined by Trenberth ot al. (2002) - see below - and requires, among other things, that climate data records be established. Satellites, for instance, are notorious for having a limited (order $5 \mathrm{yr}$ ) operational lifetime during which the instrument degrades, the orbit decays in altitude, the equator-crossing time for sunsynchronous satellites can drift, and then they are replaced on failure of a critical component thereby eliminating the possibility of comparisons with the next instrument on the next satellite that is so vital for the continuity of the climate record. Of course, having redundant systems, in particular, having a morning and afternoon polar orbiting satellite, belps bridge gaps, but issues related to the diurnal cycle of the observations combined with the harsh diurnal cycle of the platform and instrument as it moves from day to night to day have compromised obtaining high-quality long continuous records from space. Onboard calibration has also helped but can also suffer from degradation of the sensors from cosmic radiation. Examples of the difficulties can be seen for radiation in Wielicki et al. (2002) and Trenberth (2002). [The latter includes a commentary and response that includes a correction. Since then several other corrections have been applicd related to decay of the satellite altitude and instrumental drift, requiring further reprocessing of the data (Wong et al. 2006)]. The longstanding controversy over the so-called satellite temperature record is another example (sec NRC 2000; Christy et al. 2003; Mears et al. 2003; Fu ct al. 2004).

Other outstanding issues for establishing a climate information system include the ability to handle huge volumes of data in near-real time; stewardship and archival of the data; access to data in a timely fashion and with minimal incremental costs; reanalysis and reprocessing of observations; developing new parameterizations in models appropriate for higher resolutions; and managing data from ensemble projections for many years into the future.

We believe we know what is necded, but there are questions on how to accomplish it, even given that such a system is highly likely to pay for itself many times over through improved informed decision making.

\section{Climate observations}

The need for climate data records has been increasingly realized and is now documented in detail in a recent National Research Council (NRC) report (NRC 2004). This recognizes that most observations are instrument and platform dependent. At the very least, observations must be of known quality, and preferably the quality is high. However, consistency and continuity are vital and calibration is essential. Continuing analysis and integrated assessment of obscrvations are vital parts of the system that result in a usable uncertainty or error analysis. Most fundamentally needed are some "benchmark" observations: observations that approach absolute accuracy, preferably independent of instrument and platform, to anchor analyses.

For the atmosphere, the main instrument used has been the radiosonde, which is combined with satellite soundings in the infrared and microwave that are synthesized with other information in four-dimensional data assimilation. Radiosondes are independent and provide very high vertical resolution in all weather, but they have significant errors associated with representa- 
tiveness and cannot provide high-resolution global coverage. Moreover, the radiosondes suffer from biases and lack absolute accuracy; they suffer from radiation errors and low-quality humidity sensors that cannot cover the needed dynamic range throughout the troposphere, and different sonde types can have serious calibration errors (e.g., Lanzante ef al. 2003; Wang et al. 2003). An example of the effects of changing sondes is given in Christy et al. (2003) for temperatures in the lower stratosphere at the Chuuk Islands in the tropical west Pacific Ocean where the change was from Viz-B to Vaisala RS80 in December 1995 and was manifested as a spurious stratospheric cooling. Unfortunately, metadata on such changes are often missing.

The satellite systems often lack adequate calibration and are subject to effects from changes in observing times and orbital decay that challenge the continuity of record, especially as satellites and instruments change. The global coverage of satellite data complements the limited land-based coverage from radiosondes, but the vertical and horizontal resolutions differ. The combination falls far short of what is needed for climate monitoring.

In contrast, a demonstrated new technology that exploits the global positioning system (GPS) satellites through use of radio occultation (RO) soundings is emerging as a true benchmark observation (Ware et al. 1996; Kursinski et al. 1996; Leroy 1999). Radio occultation soundings have excellent long-term stability, can be made in all weather conditions, and have excellent $(<200 \mathrm{~m})$ vertical resolution, global fairly uniform coverage, diurnal cycle coverage, and many observations to beat down random noise. The horizontal representativeness of $-200-300 \mathrm{~km}$ is more compatible with current global model resolution than isolated point values from sondes and is excellent for climate purposes, although it may be limiting in the future. The observations can be used to help calibrate other remote sensing infrared or microwave systems (e.g., Schroder et al. 2003 ) but can also be integrated with those radiances in an assimilation system. The RO system would provide useful and unique vertical soundings of electron density in the ionosphere (although with some limitations), temperature in the stratosphere, and temperature and water vapor in the troposphere. Complementing other sounding techniques, these soundings or direct information on refractivity and bending angles would have many applications for space weather, climate monitoring, and numerical weather prediction. Experimental systems are in place [e.g., the Challenging Minisatellite Payload system (CHAMP; Wickert et al, 2004)] and enhanced systems are planned [the Constellation $\mathrm{Ob}$ serving System for Meteorology, Ionosphere and Climate array (COSMIC; Rocken et al. 2000), ${ }^{1}$ which is a prototype for a permanent operational constellation of at least six microsatellites in polar orbit producing $\sim 2500$ RO soundings a day globally that would support and substantially augment and improve the existing and planned global observing system at a very affordable cost.] A recent workshop advocates the use of RO measurements and discusses advantages (Bengtsson et al. 2003). Furthermore, "next-generation" developments may lead to additional enhancements (c.g., Kursinski et al. 2002).

The Global Climate Observing System (GCOS) second adequacy report (GCOS 2003) highlighted a number of "essential climate variables" for the three domains of the atmosphere, the ocean, and land surface. For the atmosphere these include (i) surface: air temperature, precipitation, air pressure, surface radiation budget, wind speed and direction, and water vapor; (ii) upper air: earth radiation budget (including solar irradiance), upper-air temperature [including microwave sounding unit (MSU) radiances], wind speed and direction, water vapor, and cloud properties; and (iii) composition: carbon dioxide, methane, ozone, other longlived greenhouse gases, and acrosol properties. For the ocean these include (i) surface: sea surface temperature (SST), sea surface salinity, sea level, sea state, sea ice, current, ocean color (for biological activity), and carbon dioxide partial pressure; and (ii) subsurface: temperature, salinity, current, nutrients, carbon, ocean tracers, and phytoplankton. For the land surface, the essential variables include river discharge, water use, groundwater, lake levels, snow cover, glaciers and ice caps, permafrost and scasonally frozen ground, albedo. land cover (including vegetation type), Fraction of $\mathrm{Ab}$ sorbed Photosynthetically Active Radiation (FAPAR), leaf area index (LAI), biomass, and firc disturbance.

Following the second adequacy report from GCOS (2003), we have proposed a thin network of order 40 stations distributed globally of high-quality "reference sondes" along the lines of those discussed by Wang et al. (2003). Water vapor, as the most important greenhouse gas, is very poorly measured yet vital for better understanding climate change. The prototype system would contain three thermisters (e.g., white, silver, and black) to provide redundancy and allow removal of radiation effects from temperatures. The chilled mirror humidity sensor is vastly superior to operational sonde humidity sensors in the troposphere but would not be suitable in the stratosphere, where a frost point hygrometer has been used to good effect at Boulder. Col-

\footnotetext{
${ }^{1}$ The six-satellite COSMIC array was successfully launched on 14 April 2006
} 
orado (Oltmans et al. 2000). It is desirable that these soundings be complemented by regular sondes as part of the Global Upper-Air Network (GUA.V) to ensure adequate temporal sampling.

Water vapor sampling can also be addressed by GPS column measurements (c.g., Ware et al. 2000; Bengtsson et al. 2003) that can be made at high temporal frequency and that therefore can fully sample the diurnal cycle and fluctuations that might otherwise alias the bascline observations. Accounting for the diurnal cycle is an important issue. The column measurements constrain the total amount.

At the surface, many new sensors have been developed and are being deployed from towers. It remains a challenge to deal properly with the heterogeneity of the land surface and many precipitation stations will continue to be needed, although preferentially with hourly data in order to capture changes in frequency and intensity of precipitation as a well as amounts (Trenberth el al. 2003). Radar measurements and an array of satellite measurements based on the proposed Global Precipitation Mission may finally allow the temporal sampling to become adequate to address hydrological issues in ways that are greatly needed.

For the ocean, while much can be done from space in terms of altimetry, scatteromctry, ocean color, surfacc salinity, sea surface temperature, precipitation, and some surface fluxes, continuing to develop the backbone of subsurface autonomous floats (ARGO) and moored buoys, complemented by expendable bathythermographs (XBTs), surface drifters, and tide gauges is vital. The initial ocean observing system is being implemented and is partially complete.

For the carbon cycle (see Ciais et al. 2004), the sources and sinks and controlling processes will only be determined within an integrated approach where pointwise in situ surface measurements can be scaled up using global satellite datasets and models, and then constrained and verified by global atmospheric $\mathrm{CO}_{2}$ concentration measurements day and night, at all latitudes, and in all seasons. Process studies must be complcmented by time series sites and moorings, Voluntary Observing Ship (VOS) surface observations, eddy covariance flux networks, transbasin sections, aircraft surveys, and remote sensing, especially laking advantage of passive and active sensors in the near infrared to obtain atmospheric carbon dioxide measurements.

Another vital component is the need to continue with a vibrant program on paleoclimate reconstructions and synthesis. This is actually by far the simplest and cheapest way to obtain long climate records to better assess the natural variability of the climate system and place current anomalies in context.
The vision we have embraces an integrated system of both in situ and satellite observations that provide global coverage but with continuity and sufficient baseline measurements so that the reality or otherwise of trends can be clearly established. It appears that the need for routine radiosondes is likely to decline except for a subset of much higher quality sondes, such as discussed above. More comprehensive sets of measurements should also be made, with the ozone sonde network better intcgrated with and even collocated with the temperature and water vapor soundings. Other variables (e.g., constituents) may also be sampled on such specialty sondes. The bulk of the information on the frec atmosphere, however, is sure to come from remote sensing from space, but it must be anchored with solid ground-based observations.

\section{Climate observing system}

A climate observing "system" means a comprehensive approach that, according to Trenberth et al. (2002), includes the following.

- Climate observations from both space-based and in situ platforms that are taken in ways that address climate needs and adhere to the 10 principles outlined by the NRC (1999). The international framework for sharing data is vital.

- A global telecommunications network and satellite data telemetry capacity to enable data and products to be disseminated.

- $\Lambda$ climate observations analysis and tracking capability that produces global and regional analyses of various products for the atmosphere, oceans, land surface and hydrology, and the cryosphere.

- Four-dimensional data assimilation capabilities that process the multivariate data in a physically consistent framework to enable production of the analyses, not just for the atmosphere, but also for the oceans, land surface, and cryosphere.

- Global climate models that encompass all parts of the climate system and that are utilized in data assimilation and in making ensemble predictions originating from the initial observed state.

- A center for climate observation oversight and observing system monitoring that tracks the performance of the observations, the gathering of the data, and the processing systems. The center must also have the resources and influence to adequatcly address issues and the capability to communicate climate requirements when observational systems are being discussed and established, such as for weather purposes or in establishing requirements for instruments on satellites. 
Many of these elements exist in some form, but most were not developed for climate purposes and fall short of what is needed for a climate information system. Observations need to be taken in ways that satisfy the climate monitoring principles and ensure long-term continuity and ability to discern small but persistent signals. The implementation of adherence to the climate principles is only partly in place and GCOS has extended the original 10 principles to embrace 10 further principles specifically oriented to satellite measurements (see GCOS 2003). Satellite observations must be calibrated and validated, with orbital decay and drift effects fully dealt with, and adequate overlap to ensure continuity. Telemetry shortfalls affect many measurements as radio frequencies are taken up for other uses (such as cell phones) and observational information, such as from ARGO floats, is constrained by telemetry capabilities and expense.

Many observations are analyzed but often require reprocessing and reanalysis for climate purposes. Fourdimensional data assimilation has been practiced for many years in the atmosphere but is still being developed for the ocean and land surface, and for the coupled system. Reanalysis of the records must be institutionalized along with continual assessment of impacts of new observing and analysis systems. Models are being used in the assimilation and for predictions, but initial states are not yet used for decadal and longer-term predictions and for climate change. Largely missing altogether is an oversight center that tracks the performance of the whole observing system, and has the capabilities and funding to fix problems before they become entrenched. Thus the health of the monitoring system must be tracked and resources identified to repair problems.

The climate community also has an obligation to continually examine the adequacy of planned satellite data in terms of its information content for characterizing and understanding climate. This includes influencing future sensors that are flown as well as the manner in which they are operated.

We believe that the earth science community should embrace the principle that no new observing system is built without adequate planning and consideration for monitoring of the observing system for random and time-dependent errors and biases, metadata that fully describe the observing system status and the environment in which it operates, the manner in which the data are processed, the means to deliver fundamental data analyses and products, and provisions for the long-term archive of the data with access to the data in a wellconceived, effective manner.

\section{Attribution}

One area of major growth should be developing the ability to not only track climate anomalies in the atmosphere but also to attribute them on multiple time scales to

- forcings external to the climate system (solar, volcanoes, and atmospheric composition);

- forcings of the atmosphere internal to the climate system [e.g., El Niño-Southern Oscillation (ENSO), SSTs, and ocean heat content, soil moisture anomalies, state of vegetation, and sea ice];

- feedbacks associated with the responses (such as changes in atmospheric composition); and

- natural atmospheric variability (essentially unpredictable).

This requires an operational numerical expcrimentation program running ensembles of models with and without these effects. At present, the activity of sorting out influences on the atmospheric anomalies is carried out in an ad hoc fashion, often as a research topic and not in real time. Institutions such as the National Oceanic and Atmospheric Administration's (NOAA's) Climate Prediction Center, the European Centre for Medium-Range Weather Forecasts, and the International Research Institute for Climatc Prediction, as well as many other national meteorological or climate centers, may perform limited experimentation in near-real time as part of the process of issuing monthly forecasts, or retrospectively to understand major anomalies. Many research organizations participate and publish results. However, models now appear to have improved sufficiently that results are becoming more definitive.

For instance, several studies have recently provided evidence that decadal anomalies of major importance can now be traced to patterns of global SSTs. These include the following:

- the sub-Saharan African drought beginning in the 1960s (e.g., Giannini et al. 2003),

- the "Dust Bowl" era in North America in the 1930s (e.g., Schubert et al. 2004),

- trends in the North Atlantic Oscillation (e.g., Hurrell et al. 2004),

- other large-scale persistent droughts (e.g., Hoerling and Kumar 2003), and

- ENSO effects (many studies),

as long as the global SSTs are given. But why are the SST anomalies the way they are?

Global SSTs in recent years have not warmed uniformly even as global warming progresses (Fig. 1). Evidently the trend pattern relates to the ways the different parts of the ocean are coupled with the atmosphere, 

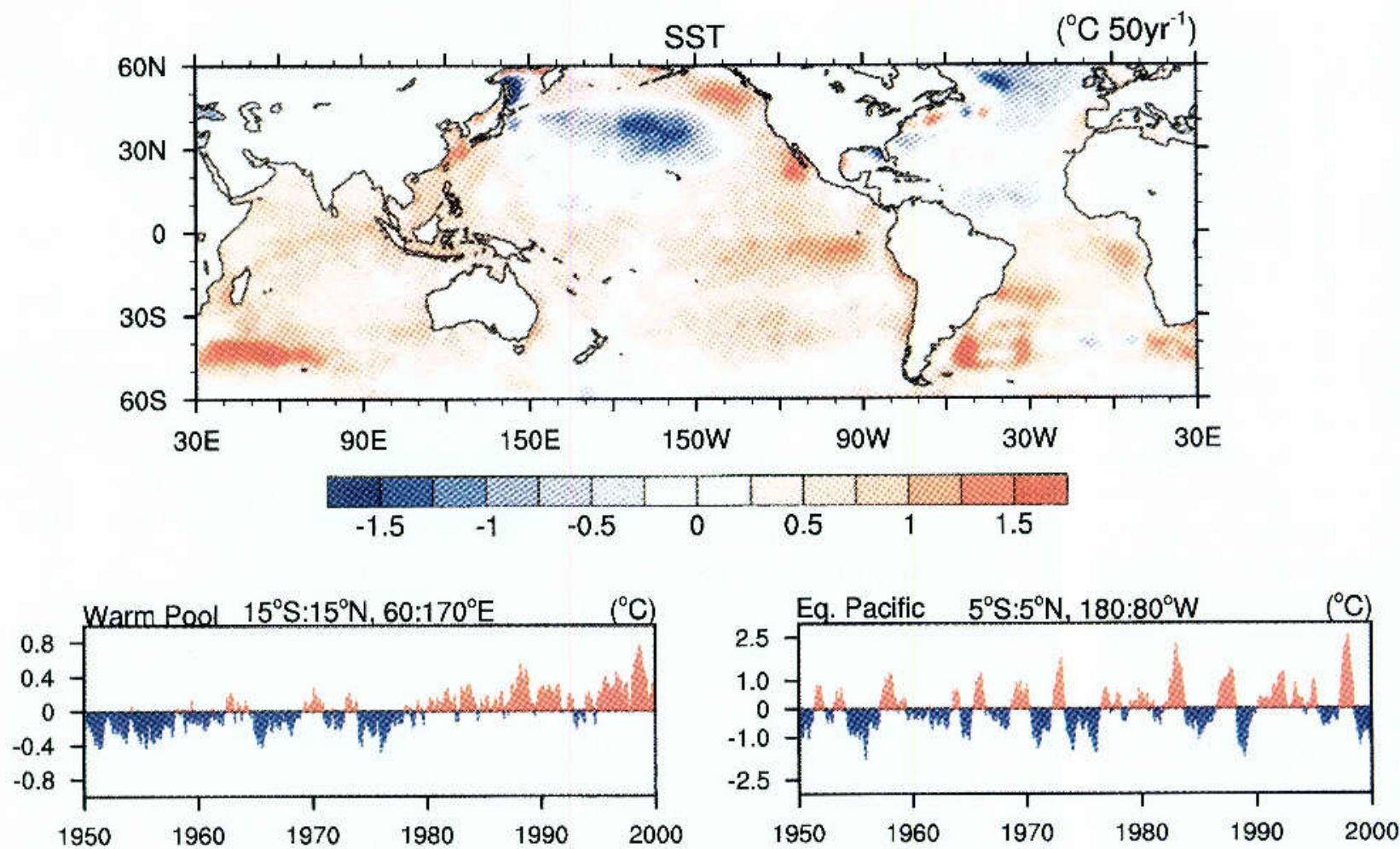

FIG. 1. (top) Trends in SST's of 1950-99 and time series of monthly SST anomalies over the (bottom left) equatorial Indian and western Pacilic Oceans and (bottom right) eastern equatorial Pacific Ocean. [Based on Hurrell et al. (2004) and kindly provided courtesy ol A. Phillips and J. Hurrell.]

which also determines the impact on the atmosphere, and relates to ocean uptake of heat, resulting occan heat content, and transport. We note that the tropical Indian Ocean has warmed to be competitive in its atmospheric influence with the Warm Pool in the tropical western Pacific as the warmest part of global ocean (Fig. 1). Mcanwhile the tropical Pacific evidently gets relicf from warming owing to ENSO; the Pacific pattern in lig. 1 of warming in the Tropics and cooling in the North Pacific is identificd with signatures of LNSO and the related Pacilic decadal oscillation (PDO). Deeper mixing occurs in the Atlantic, giving rise to the predominant thermohaline circulation (THC) in the ocean. and the pattern of trends there could relate to a slowing THC. There is considerable other oceanographic evidence, for instance related to freshening of the high latitudes and an increase in salinity in low latitudes of the North Atlantic (Dickson et al. 2003), that supports such ideas. Note how the warming in both the tropical Pacific and Indian Occans is similar in magnitude but much more significant in the Indian Ocean as the natural variability there is much less. These unique aspects of the various oceans and their consequences for SSTs lead to patterns that are currently not well simulated by coupled models, but as higher resolution and more en- compassing models are being developed, there is a sound basis for the belief that they will improve. Under the phrase "more encompassing," we look forward to seeing somc aspects of prediction on decadal time scales of changes in heat storage of oceans and associated changes in SSTs, glacicr and ice sheet melt, changes over land in soil moisture and vegetation, and associated changes in atmospheric circulation.

In any case, because the climate is changing systematically from human influences, models should show some predictive skill simply based on the current state, although the latter is not yet sufficiently well known to allow full attribution of why the current state is the way it is. Such assessments require full consideration of changes in heat storage in the various reservoirs, changes in forcings, clouds, aerosols, and water vapor, fluxes among different climate system components, and transports by the atmosphere and oceans, all of which can be integrated into a climate system model framework.

\section{The future challenge}

In summary, we believe the challenge is to better determine the following: 
TAIBIF 1. Criteria for optimizing observing systems.

\begin{tabular}{|c|c|c|}
\hline Demand criteria & Implementation criteria & Sirategic critcria \\
\hline Usefulness of existing observations & Cost to implement & Existing infrastructure to support data stewardship \\
\hline Capacily and demand & Readiness & Fasy access to data \\
\hline Dual use potential & Operating cost & Potential for transition from research to operations \\
\hline State of models for data utilization & Probability of successful implementation & Cost sharing and partnerships \\
\hline \multirow[t]{3}{*}{ Perceived impact of resulting data } & Well-defined measurement principles & Commitment and stability of sponsors \\
\hline & Fxtensibility to improvements & Absence of potential impediments to data use \\
\hline & Timeliness of data and information & Breadth and readiness of user communities \\
\hline
\end{tabular}

1) how the climate system is changing:

2) how the forcings are changing:

3) how these relate to each other;

4) what they mean for the immediate and more distant future:

5) seamless predictions on multiple time scales;

6) attribution of anomalies to causes;

7) how to use this information for informed planning and decision making;

8) how to manage the data and reanalyze it routinely:

9) how to disseminate products around the world; and

10) how to interact with users and stakeholders and add regional valuc.

A particular opportunity may arise from the developments stemming from the Earth Observing Summit held 31 July 2003, in Washington. D.C., which set up a Group on Earth Observations (GEO). This has in turn led to the Global Earth Observation System of Systems (GEOSS) 10-yr implementation plan, adopted in February 2005 and endorsed by nearly 60 governments (GEO 2005), which calls for systems to share earth observation data, identify gaps in observational efforts, and come up with ways to fill them. The basic idea behind the GEOSS is that dozens of observational systems are now generating reams of data that could be far more powerful and useful for decision making if they were combined and widely disseminated. But achieving that goal means overcoming major institutional, technical, and political hurdles. Note that this initiative embraces much more than atmospheric and climate data and includes private, national, and global observations to promote the environment, human health, safety, and welfare.

Optimizing operational observing systems for multiple users includes considerations of three kinds of criteria related to demand, implementation, and strategic aspects (Table 1). All of these will be part of scientific data stewardship.

Internationally, the World Climate Research Programme (WCRP) has launched a new initiative called the Coordinated Observation and Prediction of the
Earth System (COPES) that is a synthesizing framework designed to foster research into building a comprehensive observing and prediction system for climate. COPES will do the following:

- provide a framework for ensuring collaboration among nations and synergy across projects and activities;

- help build new tools to describe and analyze climate variability and change, and their combined effects;

- facilitate assessment of why these effects are occurring:

- enhance the building of improved and more comprehensive climate system models;

- make possible climate predictions of greater utility from weeks to centuries and on global to regional scales; and

- enable improved climate change assessments on effects of humans, changes in extremes, impacts on water resources, and many other applications.

COPES embraces all the projects within the WCRP that are often more focused on process studies but provides an overall framework that works toward building the Climate Information System envisaged here.

Together all of these components make up the climate information system as a major component of the more general Earth Information System. It clearly has many benefits that would likely more than offset costs and would certainly lead to greatly improved stewardship of the planet. In any case the need for the system is much more than purely economic as it is an ethical imperative with regard to improving planning for future generations. It is also a basis for exciting science as we discover more on how the earth system works.

Acknowledgments. The research of Trenberth is partly sponsored by NOAA under Grant NA56GP0247 and by joint NOAA/NASA Grant NA87GP0105. The research of Moore is partly sponsored by NOAA under Grant NA504NES440001 and by NASA under Grant NNG04GH75G. 


\section{REFERENCES}

Bengtsson, L., and Coauthors, 2003: The use of GPS measurements for water vapor determination. Bull. Amer. Meteor. Soc., 84, 1249-1258.

Christy, J. R.. R. W. Spencer, W. B. Norris, and W. D. Braswell. 2003: Error estimates of version 5.0 of MSU AMSU bulk atmospheric temperatures, J. Atmos. Oceanic Technol., 20, $613-629$.

Ciais, Ph., and Coauthors, 2004: Integrated Global Carbon Observation Theme: $\mathrm{A}$ strategy io realise a coordinated system of integrated global carbon cycle observations. Integrated Global Observing Strategy-Partners, $53 \mathrm{pp}$. [Available online at http//www.igbp.kva.se.]

Dickson, R. R., R. Curry, and I. Yashayaev, 2003: Recent changes in the North Allantic. Philos. Trans. Roy, Soc, London, 361A, 1917-1934.

Fu, Q., C. M. Johanson, S. G. Warren, and D. J. Seidel, 2004: Contribution of stratospheric cooling to satellite-inferred tropospheric temperature trends. Nature, 429, 55-58.

GCOS, 2003: The second report on the adequacy of the global observing systems for climate in support of the UNFCCC. Rep. GCOS-82, WMO/TD No. 1143, 74 pp.

GEO, 2005: Global Earth Observation System of Systems GFOSS: 10-year implementation plan reference document. Group on Earth Obscrvations Rep. GEO 1000R/ESA SP$1284.209 \mathrm{pp}$.

Giannini, A., R. Saravanan, and P. Chang, 2003: Oceanic forcing of Sahel rainfall on interannual to interdecadal time scales. Sicience, 302, 1027-1030.

Hocrling, M., and A. Kumar, 2003; The perfect ocean for drought. Science, 299, 691-694.

Hurrell, J. W.. M. P. Hoerling, A. S. Phillips, and T. Xu. 2004: Twentieth century North Allantic climate change. Part I: Assessing determinism. Climate Dyn., 23, 371-389.

Karl, T. R., and K. E. Trenberth, 2003: Modern global climate change. Science, 302, 1719-1723

Kursinski. E. R., and Coauthors, 1996: Initial results of radio occultation obscrvations of Earth's atmosphere using the global positioning system. Science, 271, 11071110 .

, S. Syndergaard, D. Flittner, D. Feng, G. Hajj, B. Herman, D. Ward, and '1: Yunck, 2002: A microwave occultation observing system optimized to characterize atmospheric water, temperature, and geopotential via absorption. J. Almos. Oceanic Technol., 19, 1897-1914.

Lanzante. J. R., S. A. Klcin, and D. J. Seidel, 2003: Temporal homogenization of monthly radiosonde lemperature data. Part I: Methodology. J. Climate, 16, 224-240.

Leroy, S. S., 1999: Optimal detection of global warming using temperature profiles: A methodology. J. Climate, 12, 1185-1198.

Lohmann. D, and Coauthors, 2004: Streamflow and water balance intercomparisons of four land surface models in the North American Land Data Assimilation System project. $I$. Geophys. Res., 109, D07S91, doi:10.1029:2003J1)003517.

Mears, C. A., M. C. Schabel, and F. J. Wenlz. 2003: A reanalysis of the MSU channel 2 tropospheric temperature record, $J$. Climate, 16, 3650-3664.

Mitchell, K. E., and Coauthors, 20104: The multi-institution North American Land Data Assimilation System (NLDAS): Litiliz- ing multiple GCIP products and partners in a continental distributed hydrological modeling system. I. Geophys. Res., 109, D07S90, doi:10.1029/2003JD003823.

NRC, 1999: Adequacy of Climate Observing Systems. National Academy Press, $51 \mathrm{pp}$.

, 2000: Reconciling Observations of Glohal Temperature Change. National Academy Press, 85 pp.

2004: Climate Data Records from Environmental Satcllites: Interim Report. National Academy Press, $105 \mathrm{pp}$.

Oltmans, S. J., H. Vomel, D. J. Holmann, K. H. Rosenlof, and D. Kley, 2000: The increase in stratospheric water vapor from balloon borne frost-point hygrometer measurcments at Washington, D.C., and Boulder, Colorado. Geophys. Res. Lett., 27, 3453-3456.

Rocken, C., Y.-H. Kuo, W. S. Schreiner, D. Hunt, S. Sokolovskiy, and C. McCormick, 2000: COSMIC system description. Terr. Amos. Oceanic Sci. 11, 21-52.

Schrøder, T., S. Leroy, M. Stendel, and E. Kaas, 2003: Validating the microwave sounder unit stratospheric record using GPS occultation data. Geophys. Res. Lett., 30, 1734, doi:10.1029/ 2003 GLO17588.

Schubert, S. D., M. J. Suarě, P. I. Region, R. D. Koster, and J. T' Bacmeister, 2004: Causes of long-term drought in the United States Great Plains. f. Climate, 17, 485-503.

Trenberth, K. E., 2002: Changes in tropical clouds and radiation: Are they real? Science, 296, 2095a. [Available online at hitp: www.sciencematg.org/cgi/content/fulli296/5576/2095a.]

_, T. R. Karl, and T. W. Spence, 2002: The need for a systems approach to climate observations. Bull. Amer. Meteor. Soc., $83,1558-1559$

-, A. Dai. R. M. Rasmussen, and D. B. Parsons, 2003: The changing character of precipitation, Bull. Amer. Meteor. Soc., 84, $1205-1217$.

Wang, J., D. J. Carlson, D. B. Parsons, T. F. Hock, D. Lauritsen, II. L. Cole, K. Beierle, and F. Chamberlain, 2003: Performance of operational radiosonde humidity sensors in direct comparison with a chilled mirror dew-point hygrometer and its climate implication. Geophys. Res. Lett., 30, 1860, doi: $10.1029 ; 2003(31016985$.

Ware, R., and Coauthors, 1996: GPS sounding of the atmosphere from low Earth orbit: Preliminary results. Bull. Amer. Meteor. Soc., 77, 19-40.

— and Coauthors, 2000: SuomiNet: A real-time national GPS network for atmospheric research. Bull. Amer. Meteor. Soc, 81, 677-694.

Wickert, J., 'I. Schmidt, G. Beyerle, R. Konig, C. Reigber, and N. Jakowski, 2004: The radio occultation experiment aboard CHAMP: Operational data analysis and validation of vertical atmospheric proliles. J. Meteor, Soc. Japan, 82, 381-395.

Wielicki, B. A., and Coauthors, 2002: Lividence for large decadal variability in the tropical mean radiative energy budget. Science, 295, 841-844.

Wong, T., B. A. Wielicki, R. B. I.ee III, G. L. Smith, and K. A. Bush, 2006: Recxamination of the observed decadal variahility of the Larth Radiation Budget using altitude-corrected ERBF/ERBS nonscanner WFOV data. J. Climate, 19, 40284040 . 


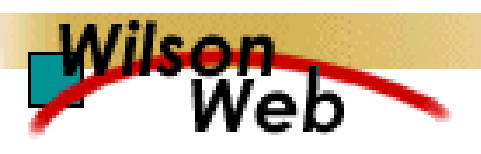

\section{COPYRIGHT INFORMATION}

TITLE: Monitoring and Prediction of the Earth's Climate: A Future Perspective

SOURCE: J Clim 19 no20 O 152006

WN: 0628807462004

The magazine publisher is the copyright holder of this article and it is reproduced with permission. Further reproduction of this article in violation of the copyright is prohibited.

Copyright 1982-2006 The H.W. Wilson Company. All rights reserved. 